\title{
Preferential Neuronal Loss in Layer III of the Medial Entorhinal Cortex in Rat Models of Temporal Lobe Epilepsy
}

\author{
Fu Du, ${ }^{1}$ Tore Eid, ${ }^{1,4}$ Eric W. Lothman, ${ }^{2, a}$ Christer Köhler, ${ }^{3}$ and Robert Schwarcz ${ }^{1}$ \\ 'Maryland Psychiatric Research Center, University of Maryland School of Medicine, Baltimore, Maryland, \\ ${ }^{2}$ Department of Neurology, University of Virginia Medical Center, Charlottesville, Virginia, ${ }^{3}$ Pharma Division, \\ Preclinical Research, F. Hoffmann-La Roche AG, Basel, Switzerland, and ${ }^{4}$ Department of Anatomy and Cell \\ Biology, University of Bergen, Bergen, Norway
}

\begin{abstract}
We recently described a pronounced neuronal loss in layer III of the entorhinal cortex (EC) in patients with intractable temporal lobe epilepsy (Du et al., 1993a). To explore the pathophysiology underlying this distinct neuropathology, we examined the EC in three established rat models of epilepsy using Nissl staining and parvalbumin immunohistochemistry. Adult male rats were either electrically stimulated in the ventral hippocampus for $\mathbf{9 0} \mathrm{min}$ or injected with kainic acid or lithium/pilocarpine. Animals were observed for behavioral changes for up to $6 \mathrm{hr}$ and were killed $24 \mathrm{hr}$ or 4 weeks after the experimental treatments. At 24 $\mathrm{hr}$, all animals that had exhibited a bout of acute status epilepticus showed a consistent pattern of neuronal loss in the EC in Nissl-stained sections. Neurodegeneration was most pronounced in layer III of the medial EC at all dorsoventral levels. A few surviving neurons were frequently present in the lesioned area. An identical pattern of nerve cell loss was also seen in the EC of rats killed 4 weeks following the treatments. This lesion was completely prevented by an Injection of dlazepam and pentobarbital, given $1 \mathrm{hr}$ after kainic acid administration. Immunohistochemistry demonstrated a relative resistance of parvalbuminpositive neurons in layer III of the medial EC. Taken together, these experiments indicate that prolonged seizures cause a preferential neuronal loss in layer III of the medial EC and that this lesion may be related to a pathological elevation of intracellular calcium ion concentrations.
\end{abstract}

[Key words: calcium-binding protein, entorhinal cortex, kainic acid, neurodegeneration, pilocarpine, seizures, temporal lobe epilepsy]

Comprehensive clinical and pathophysiological studies have revealed a unique and stereotyped syndrome that accounts for the majority of cases of intractable epilepsy, the mesial temporal lobe epilepsy syndrome (reviewed by Wieser et al., 1993). The patients often experience status epilepticus or prolonged febrile

\footnotetext{
Received Feb. 27, 1995; revised May 1, 1995; accepted May 8, 1995.

We gratefully acknowledge the excellent technical support of Mr. John Williamson and the expert secretarial asssistance of Mrs. Joyce Burgess. This work was supported by USPHS Grants NS 16102 (to R.S., E.W.L., and F.D.) and NS 21671 (to E.W.L.), a grant from the Epilepsy Foundation of America (to F.D.), and a Fulbright Senior Scholarship (to T.E.).

Correspondence should bc addressed to Fu Du, M.D., Ph.D., Maryland Psychiatric Research Center, P.O. Box 21247, Baltimore, MD 21228.

${ }^{a}$ We are saddened by the passing of our esteemed colleague, Dr. Eric W. Lothman, and dedicate this article to his memory.

Copyright (C) 1995 Society for Neuroscience $0270-6474 / 95 / 156301-13 \$ 05.00 / 0$
}

convulsions in early life and then, after a latency period of several years, begin to suffer from repetitive temporal lobe seizures. These seizures are difficult to control with medications, but can often be abolished by surgical intervention. Histological examination of hippocampal specimens from these patients frequently reveals Ammon's horn sclerosis, with loss of neurons and gliosis in CA1, CA3, and in the dentate hilus (Sommer, 1880; Margerison and Corsellis, 1966; Babb and Brown, 1987; Bruton, 1988). Although it is still not clear whether and how these neuropathological changes are linked to the cause of chronic temporal lobe epilepsy, Ammon's horn sclerosis is commonly accepted as a hallmark of the disease. Moreover, it is widely believed that Ammon's horn sclerosis can be caused by status epilepticus (Meldrum and Bruton, 1992), although this idea is still somewhat controversial (reviewed in Lothman and Bertram, 1993).

In examining specimens obtained at the time of surgery for medically intractable temporal lobe epilepsy, we noted a characteristic pattern of neuronal loss, along with gliosis, in layer III of the entorhinal cortex (EC) (Du et al., 1993a). Notably, some neurons in the lesioned area appeared to be relatively resistant to degeneration. This distinctive neuropathology, which was most prominent in the anterior portion of the medial EC, led us to hypothesize that this lesion is implicated in the pathophysiology of temporal lobe epilepsy.

Since the study of human brain specimens has obvious limitations, we decided to examine the putative seizure-related damage to the EC, in particular layer III, in three animal models of chronic epilepsy. Our experiments included the systemic administration of chemical agents [kainic acid (KA) or lithium/pilocarpine] and electrical stimulation of the ventral hippocampus (Ben-Ari et al., 1980; Honchar et al., 1983; Turski et al., 1983; Lothman et al., 1989, 1990). A common theme of the three models is a period of acute status epilcpticus followed wecks later by recurring spontaneous hippocampal seizures and by hippocampal neuropathology that resembles Ammon's horn sclerosis (Cavalheiro et al., 1982, 1991; Ben-Ari, 1985; Olney et al., 1986; Bertram et al., 1990; Lothman et al., 1990; Du et al., 1993b).

Two time points, $24 \mathrm{hr}$ and 4 weeks after the experimental treatments, were chosen to assess histopathological changes. In addition, to test the causal relationship between prolonged seizures and neuronal loss, pharmacological intervention with anticonvulsants to arrest status epilepticus was applied to a group of rats that had received KA. Since the resistance of neurons to seizure-related destruction has been linked to their ability to 

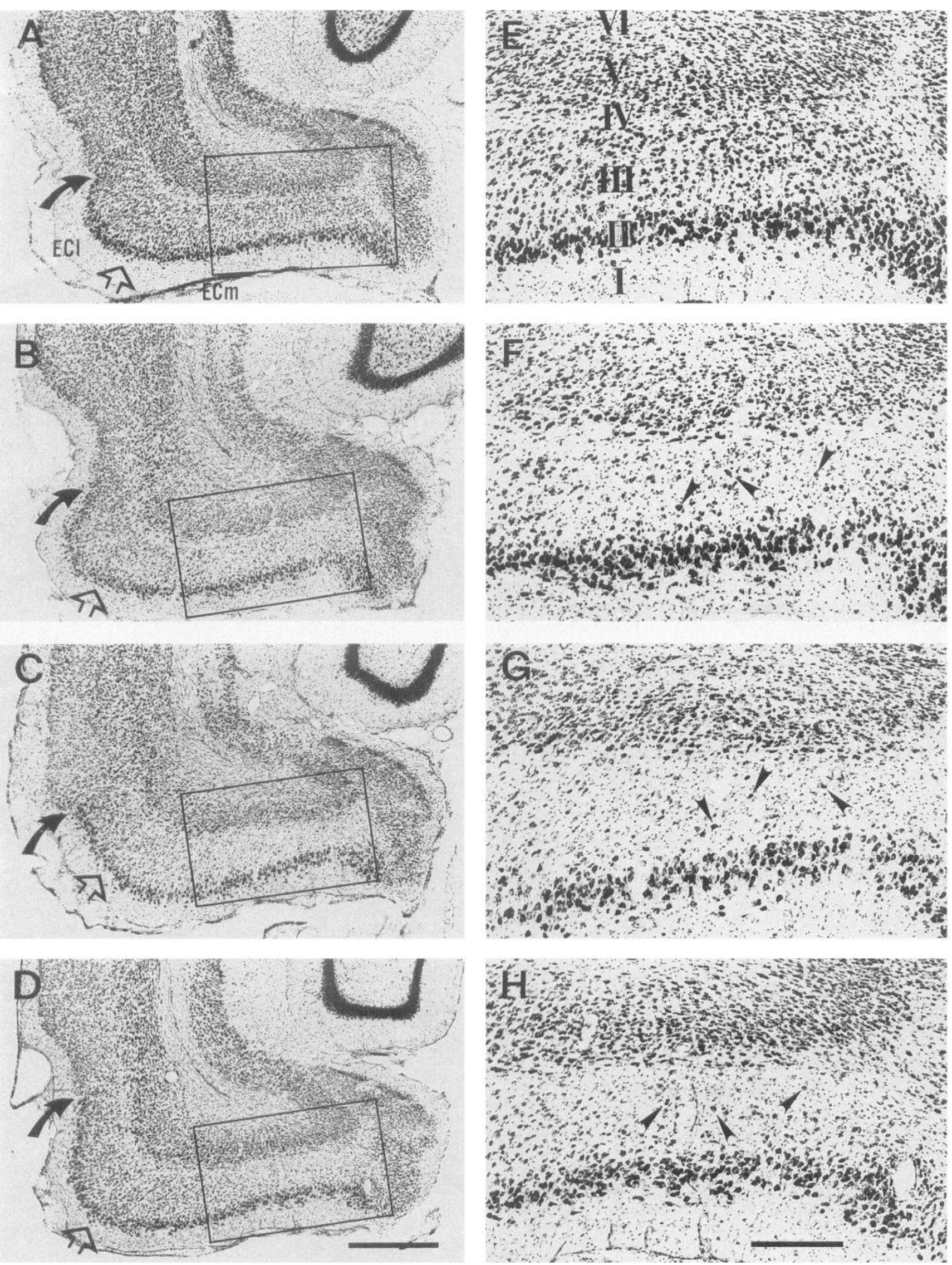
buffer intracellular free calcium (Scharfman and Schwartzkroin, 1989; Sloviter, 1989), our analysis of Nissl-stained material was combined with an immunohistochemical evaluation of the EC using an antibody against the calcium-binding protein, parvalbumin. Taken together, these experiments were expected to provide a better understanding of the causes and mechanisms of the preferential neuronal loss in layer III of the human EC.

A preliminary account of this work has appeared in abstract form (Eid et al., 1993).

\section{Materials and Methods}

\section{Animals}

Male Sprague-Dawley rats $(250-300 \mathrm{gm})$, kept at a $12 \mathrm{~L}: 12 \mathrm{D}$ cycle with free access to food and water, were used in all experiments. There were three experimental groups: (1) animals that experienced self-sustaining limbic status epilepticus (SSLSE) precipitated by electrical stimulation, (2) animals with status epilepticus precipitated by KA, and (3) animals with status epilepticus precipitated by lithium/pilocarpine. Control animals received either saline injections or a hippocampal electrode implantation.

\section{Treatment paradigms}

SSLSE. The experimental procedure to produce SSLSE has been described previously (Lothman et al., 1989, 1990). Briefly, under ketamine-xylazine anesthesia, bipolar electrodes were stereotaxically implanted in the CA3 subfield of the left ventral hippocampus (AP: 3.6 $\mathrm{mm}$ behind bregma, L: $4.9 \mathrm{~mm}$, DV: $5.0 \mathrm{~mm}$ below dura; incisor bar: $+5.0 \mathrm{~mm}$ ). One week after surgery, the experimental animals received a continuous electrical stimulation that lasted $90 \mathrm{~min}$. The animals were killed $24 \mathrm{hr}(n=6)$ or 4 weeks $(n=6)$ following the induction of SSLSE, and their brains were processed for histological analysis (cf. below). Implanted rats that received no electrical stimulation and were sacrificed 4 weeks after electrode implantation served as controls $(n=$ 6).

Injection of chemoconvulsants. KA, pilocarpine lydrochloride, lithium chloride, and (-)scopolamine methyl nitrate were purchased from Sigma Chemical Co. (St. Louis, MO). Diazepam and sodium pentobarbital were obtained from Hoffmann-La Roche (Nutley, NJ) and Abbott Laboratories (Chicago, IL), respectively. All other chemicals used were purchased from Sigma. Drugs were dissolved in $0.9 \% \mathrm{NaCl}$ (saline) and injected subcutaneously (s.c.). Nineteen rats received a dose of $10 \mathrm{mg} /$ kg KA (24 hr time point: $n=9 ; 4$ week time point: $n=10$ ). For lithium/pilocarpine treatment ( $24 \mathrm{hr}$ time point: $n=11$; 4 week time point: $n=6)$, rats were first injected with lithium $(127 \mathrm{mg} / \mathrm{kg})$ and, 24 hr later, with scopolamine $(1 \mathrm{mg} / \mathrm{kg})$ followed after $30 \mathrm{~min}$ by pilocarpine $(30 \mathrm{mg} / \mathrm{kg}$ ) (Honchar et al., 1983; Turski et al., 1983). Since prolonged convulsions substantially increases mortality in these animals, all lithium/pilocarpine-treated rats described in this article also received an injection of diazepam $(10 \mathrm{mg} / \mathrm{kg}$ ) and sodium pentobarbital $(30 \mathrm{mg} /$ $\mathrm{kg}) 4 \mathrm{hr}$ after the onset of clonic forelimb convulsions (Olney et al., 1986; Cavalheiro, personal communication). Control rats were injected (s.c.) with saline $(n=6)$, KA $(6 \mathrm{mg} / \mathrm{kg} ; n=5)$, or lithium $(127 \mathrm{mg} /$ $\mathrm{kg})$ and, $24 \mathrm{hr}$ later, scopolamine $(1 \mathrm{mg} / \mathrm{kg})(n=5)$.

Administration of anticonvulsants. Separate groups of KA-treated animals received a s.c. injection of diazepam $(10 \mathrm{mg} / \mathrm{kg})$ and pentobarbital $(30 \mathrm{mg} / \mathrm{kg})$ either $1 \mathrm{hr}$ after the administration of $\mathrm{KA}(n=8)$ or $1 \mathrm{hr}$ after the onset of clonic forelimb convulsions $(n=9)$. All animals were killed $24 \mathrm{hr}$ after $\mathrm{KA}$ administration.

\section{Tissue preparation}

After a survival time of $24 \mathrm{hr}$ or 4 weeks, all animals were deeply anesthetized with chloral hydrate $(600 \mathrm{mg} / \mathrm{kg}$, i.p.) and perfused via the ascending aorta with $50-100 \mathrm{ml}$ of saline followed by $500 \mathrm{ml}$ of $0.1 \mathrm{M}$ phosphate buffer (PB; pH 7.4) containing 4\% paraformaldehyde. The brains were removed and postfixed in the same fixative for $4 \mathrm{hr}$ at $4^{\circ} \mathrm{C}$. Following immersion in $0.1 \mathrm{M}$ phosphate-buffered saline (PBS; $\mathrm{pH} 7.4$ ) containing $20 \%$ sucrose for $48 \mathrm{hr}\left(4^{\circ} \mathrm{C}\right)$, the brains were rapidly frozen and stored at $-80^{\circ} \mathrm{C}$

Cryostat sections $(30 \mu \mathrm{m})$ were cut coronally through the anterior portion of the brain (including the dorsal hippocampus) and horizontally through the remainder of the brain, which contained the ventral hippocampus and the EC. Every first section of each series of five was mounted on gelatin-coated slides and was stained with thionin for histological analysis. In addition, representative horizontal sections from different levels along the dorsoventral axis of the EC were collected in cold PBS for immunohistochemical experiments.

\section{Immunohistochemical procedure}

A monoclonal antibody against parvalbumin (Sigma) was used. The immunohistochemical procedure has been described in detail previously (Du et al., 1993b). In brief, sections were incubated for $3 \mathrm{~d}$ at $4^{\circ} \mathrm{C}$ freefloating in PBS $(0.01 \mathrm{M}, \mathrm{pH} 7.4)$ containing anti-parvalbumin $(1: 4000)$ antibody, $3 \%$ normal horse serum and $0.3 \%$ Triton X-100. Subsequently, the immunoreaction product was visualized according to the avidinbiotin complex $(\mathrm{ABC})$ method using a standard $\mathrm{ABC}$ kit (Vectastain, Burlingame, $\mathrm{CA}$ ) and diaminobenzidine as a chromogen. Immunostained sections were mounted on slides and counterstained with thionin.

\section{Cell counting}

To examine the possible differential susceptibility of parvalbumin-immunoreactive $(-i)$ neurons to seizure-related neuronal damage, the numbers of parvalbumin-i neurons and Nissl-stained neurons were evaluated in layer III of the medial EC at three levels along the dorsoventral axis in normal and KA-treated rats. Neuronal counting was performed on immunostained sections counterstained with thionin with an ocular grid $\left(0.0196 \mathrm{~mm}^{2}\right.$ per section). Per rat, two sections were chosen from each of the dorsal, middle, and ventral level (approximately corresponding to the first, third, and fifth levels, as illustrated in Fig. 3) of the EC. Six normal and six KA-treated rats were used for cell counting. Only neuronal profiles with a visible nucleus and/or a complete cell contour were counted. (Since the same counting method was used to estimate cell densities in both experimental and normal animals, common morphometric bias errors were assumed to be negligible in the context of the present comparative analysis.) On every section, counting was performed in two different fields in layer III of the medial EC. Subsequently, the cell numbers obtained from each rat were averaged for each of the three levels along the dorsoventral axis, and the mean numbers were used for statistical analysis.

\section{Nomenclature}

The parcellation and terminology of the rat EC used in this study was based on publications by Lorente de Nó (1933) and Witter et al. (1989). Thus, the EC was divided into a medial and a lateral portion in most horizontal planes (the most dorsal portion of the EC contains only the medial EC; cf. Caballero-Bleda and Witter, 1993, Fig. 4). In Nisslstained horizontal sections, six layers can be identified in both the medial and the lateral EC based on the morphology, arrangement, and density of neurons. Layer I, the most superficial layer, contains very few neurons. Layer II is characterized by a thin assembly of relatively large neurons, which, in the lateral EC, are frequently arranged in clusters. Layer III is the widest layer of the EC and contains medium- to large-sized neurons. Layer IV is a thin layer containing both large and small neurons. Large neurons are often fusiform in shape and arranged parallel to the long axis of the lamina. Layer V consists of small, often intensely stained, neurons and has the highest neuronal density in the

$\leftarrow$

Figure 1. Photomicrographs of Nissl-stained horizontal sections $(30 \mu \mathrm{m})$ cut through the dorsal portion of the entorhinal cortex (EC) from a saline-treated $(A)$, a SSLSE $(B)$, a KA $(C)$ - and a lithium/pilocarpine $(D)$-injected rat that survived for 24 hr after the treatment. $F-H$ are higher magnifications of the areas outlined by the boxes in $A-D$, respectively. Loss of neurons is most pronounced in layer III of the medial EC in all three seizure models. Note surviving neurons in the degenerated area (indicated by arrowheads in $F-H$ ). The solid arrows in $A-D$ point to the lateral limit of the $\mathrm{EC}$ and the open arrows indicate the approximate border between the medial $(E C m)$ and lateral $(E C l) \mathrm{EC}$. $I-V I$ : layers of the EC. Scale bars: $500 \mu \mathrm{m}$ in $D$ and also for $A-C ; 200 \mu \mathrm{m}$ in $H$ and also for $E-G$. 

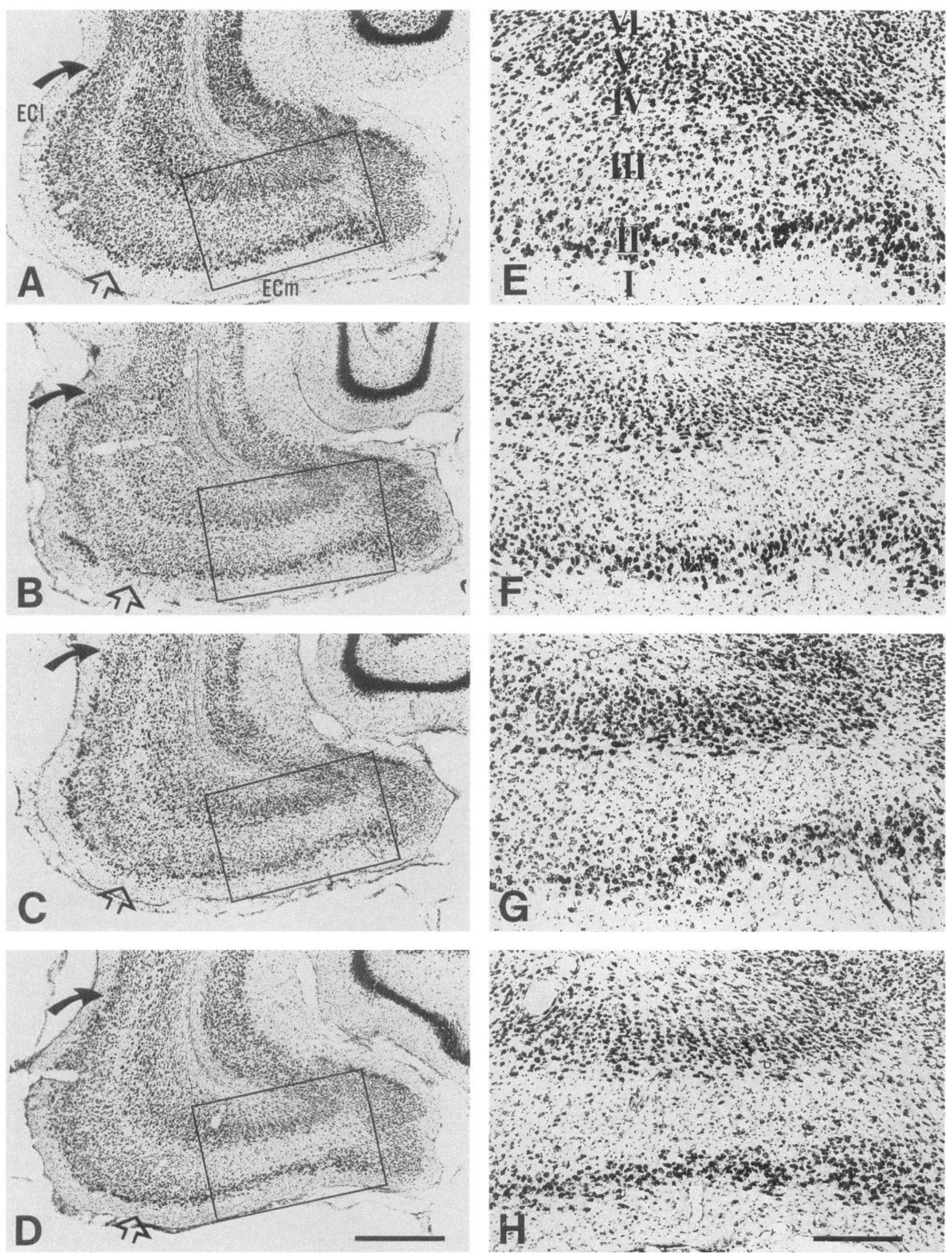

Figure 2. Nissl-stained horizontal sections $(30 \mu \mathrm{m})$ through the ventral level of the entorhinal cortex (EC) taken from the same rats as shown in Figure $1 A-H$. (cf. Fig. $1 A-H$ for the definition of the labels and abbreviations). Note prominent neuronal loss in layer III in the most medial sector of the medial EC. Scale bars: $500 \mu \mathrm{m}$ in $D$ and also for $A-C ; 200 \mu \mathrm{m}$ in $H$ and also for $E-G$. 
Table 1. Relative densities of parvalbumin-immunoreactive and Nissl-stained neurons in layer III of the rat medial entorhinal cortex: effect of KA treatment

\begin{tabular}{|c|c|c|c|c|c|c|c|c|c|}
\hline & \multicolumn{3}{|c|}{ Dorsal level } & \multicolumn{3}{|c|}{ Middle level } & \multicolumn{3}{|c|}{ Ventral level } \\
\hline & Parv. & Nissl & $\%$ & Parv. & Nissl & $\%$ & Parv. & Nissl & $\%$ \\
\hline \multicolumn{10}{|l|}{ Normal rats } \\
\hline$\# 1$ & 4.3 & 38.3 & 11.2 & 6.3 & 47.3 & 13.3 & 5.1 & 53.4 & 9.6 \\
\hline$\# 2$ & 5.0 & 42.5 & 11.8 & 4.8 & 45.8 & 10.5 & 3.8 & 53.5 & 7.1 \\
\hline$\# 3$ & 5.3 & 41.0 & 12.9 & 6.3 & 46.3 & 13.6 & 4.0 & 50.8 & 7.9 \\
\hline$\# 4$ & 5.5 & 42.3 & 13.0 & 5.5 & 46.3 & 11.9 & 3.5 & 50.5 & 7.9 \\
\hline$\# 5$ & 4.3 & 46.8 & 9.2 & 4.3 & 54.3 & 7.9 & 4.8 & 61.3 & 7.8 \\
\hline$\# 6$ & 5.0 & 45.5 & 11.0 & 6.3 & 45.0 & 14.0 & 3.5 & 54.8 & 6.4 \\
\hline Mean \pm SEM & $4.9 \pm 0.2$ & $42.7 \pm 1.2$ & $11.5 \pm 0.6^{*}$ & $5.6 \pm 0.4$ & $47.5 \pm 1.4$ & $11.9 \pm 1.0^{*}$ & $4.1 \pm 0.3$ & $54.1 \pm 1.6$ & $7.8 \pm 0.4$ \\
\hline \multicolumn{10}{|l|}{ KA-treated rats } \\
\hline$\# 1$ & 3.0 & 22.3 & 13.5 & 5.5 & 22.5 & 24.4 & 3.5 & 19.0 & 18.4 \\
\hline$\# 2$ & 3.3 & 19.5 & 16.9 & 3.0 & 10.3 & 29.1 & 3.0 & 10.3 & 29.1 \\
\hline$\# 3$ & 2.5 & 3.3 & 75.8 & 4.8 & 6.5 & 73.8 & 3.8 & 8.8 & 43.2 \\
\hline$\# 4$ & 5.5 & 39.0 & 14.1 & 3.3 & 23.3 & 14.2 & 3.3 & 21.8 & 15.1 \\
\hline$\# 5$ & 4.5 & 35.8 & 12.6 & 4.8 & 29.3 & 16.4 & 4.0 & 28.5 & 14.0 \\
\hline$\# 6$ & 3.5 & 6.0 & 58.3 & 4.3 & 9.5 & 45.3 & 3.5 & 12.8 & 27.3 \\
\hline Mean \pm SEM & $3.7 \pm 0.4$ & $21.0 \pm 6.0$ & $31.9 \pm 11.4$ & $4.3 \pm 0.4$ & $16.9 \pm 3.8$ & $33.9 \pm 9.2$ & $3.5 \pm 0.1$ & $16.9 \pm 3.1$ & $24.5 \pm 4.5$ \\
\hline$p$-Value & 0.037 & 0.005 & 0.104 & 0.034 & $<0.001$ & 0.038 & 0.084 & $<0.001$ & 0.004 \\
\hline
\end{tabular}

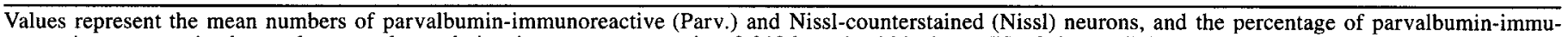

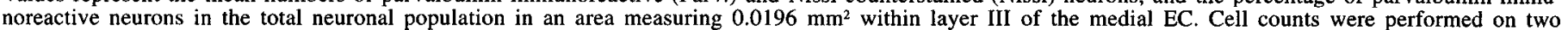

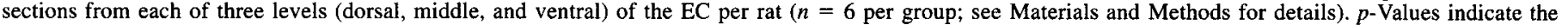
statistical significance in the differences between normal and KA-treated animals (two-tailed Student's $t$ test).

$* p<0.01$ as compared to the ventral level (one-way ANOVA followed by Dunnett's multiple comparison test).

EC. Compared to layer V, layer VI displays a relatively low density of neurons, which are rather heterogeneous in both shape and size.

\section{Results}

\section{Behavioral observations}

Behavioral observations were made in all animals for up to $6 \mathrm{hr}$ after electrical stimulation or administration of the chemoconvulsants. The behavioral and electrographic events observed in the SSLSE group were as described before (Lothman et al., 1989). Thus, during many hours of electrographic status epilepticus animals showed decreased responsiveness and sporadic "limbic seizures" with head bobbing, chewing, and whisker twitching. Convulsive events were absent or rare. SSLSE therefore conforms to a condition of nonconvulsive status epilepticus, as corroborated by electrographic recordings. In agreement with previous reports (Schwob et al., 1980; Lothman and Collins, 1981; Nadler, 1981; Honchar et al., 1983; Clifford et al., 1987; Turski et al., 1989), rats that received KA showed behavioral changes similar to those displayed by animals treated with lithium/pilocarpine. Shortly after the treatments, the rats displayed a frozen posture, followed by automatisms such as head bobbing, sniffing, chewing, and blinking. These manifestations were often interrupted by increased locomotor activity and wet dog shakes. Approximately $30 \mathrm{~min}$ after the administration of lithium/pilocarpine or $90 \mathrm{~min}$ after the injection of KA, convulsive seizures commenced. Typically, seizure episodes were characterized by vigorous chewing and head bobbing, which developed into forelimb clonus and rearing. During clonic convulsions, many rats lost their balance and showed excessive salivation. Some animals also exhibited generalized clonic convulsions that affected the whole body and terminated in a tonic phase. Episodes of convulsive seizures recurred frequently, and in many animals lasted to the end of the observation period. No behavioral seizures were observed in control animals.

Rats that received injections of KA and diazepam/pentobarbital fell asleep shortly after the anticonvulsive treatment. Upon awakening, no behavioral seizure activity was noted in these animals until the end of the observation period.

\section{Histopathological observations: general comments}

In the following description, disappearance of Nissl staining in neurons is equated with neurodegeneration, neuronal loss, or neuronal damage, though the loss of Nissl staining does not necessarily indicate the physical disappearance of dead cells. Notably, similar morphological alterations were found in the brains of rats that survived for either $24 \mathrm{hr}$ or 4 weeks following the treatments. No neuronal loss was detected in any brain region of control rats. In agreement with prior studies (Schwob et al., 1980; Nadler, 1981; Honchar et al., 1983; Turski et al., 1983; Ben-Ari, 1985; Clifford et al., 1987; Du et al., 1993b), neurodegeneration was detected in several brain regions in SSLSE, KAor lithium/pilocarpine-injected rats. Although subtle differences in the severity and location of these lesions were noticed among the three experimental models, neuronal damage in the hippocampus, the thalamus, and various neocortical regions was found to be a common feature in the brains of these animals. In addition, loss of neurons was consistently observed in layer III of the medial EC in all three models of epilepsy. In accordance with the purpose of the present study (cf. introductory paragraphs), only characteristics of this EC lesion are described in detail below. 


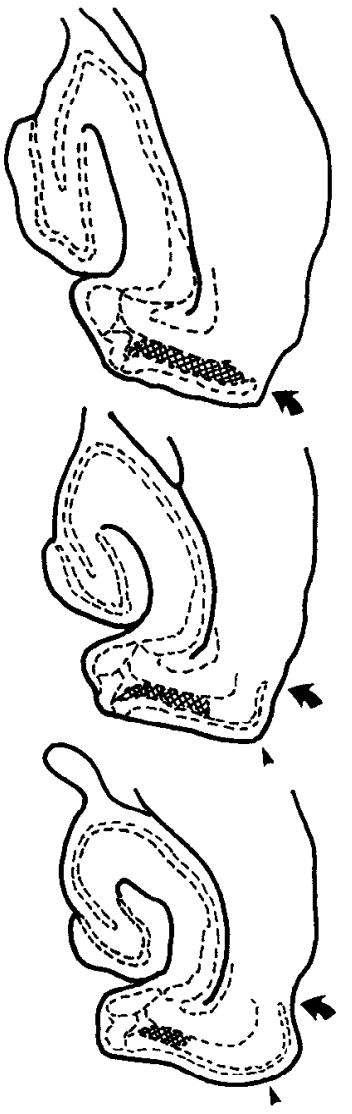

Figure 3. Camera lucida drawings from Nissl-stained horizontal sectons cut through the entorhinal cortex (EC) of a representative SSLSE, KA-, and lithium/vilocarpine-injected rat killed $24 \mathrm{hr}$ after the treatment, showing typical neuronal loss in layer III at different levels along the dorsoventral axis. The shaded area represents the extent of the visible lesion along the mediolateral axis in layer III. Arrows indicate the lateral limit of the EC, and arrowheads point to the approximate border between the medial $(E C m)$ and lateral $(E C l) \mathrm{EC}$. Note that the lesion in layer III is always present in and frequently restricted to the most medial sector of the medial EC.

\section{SSLSE}

KA
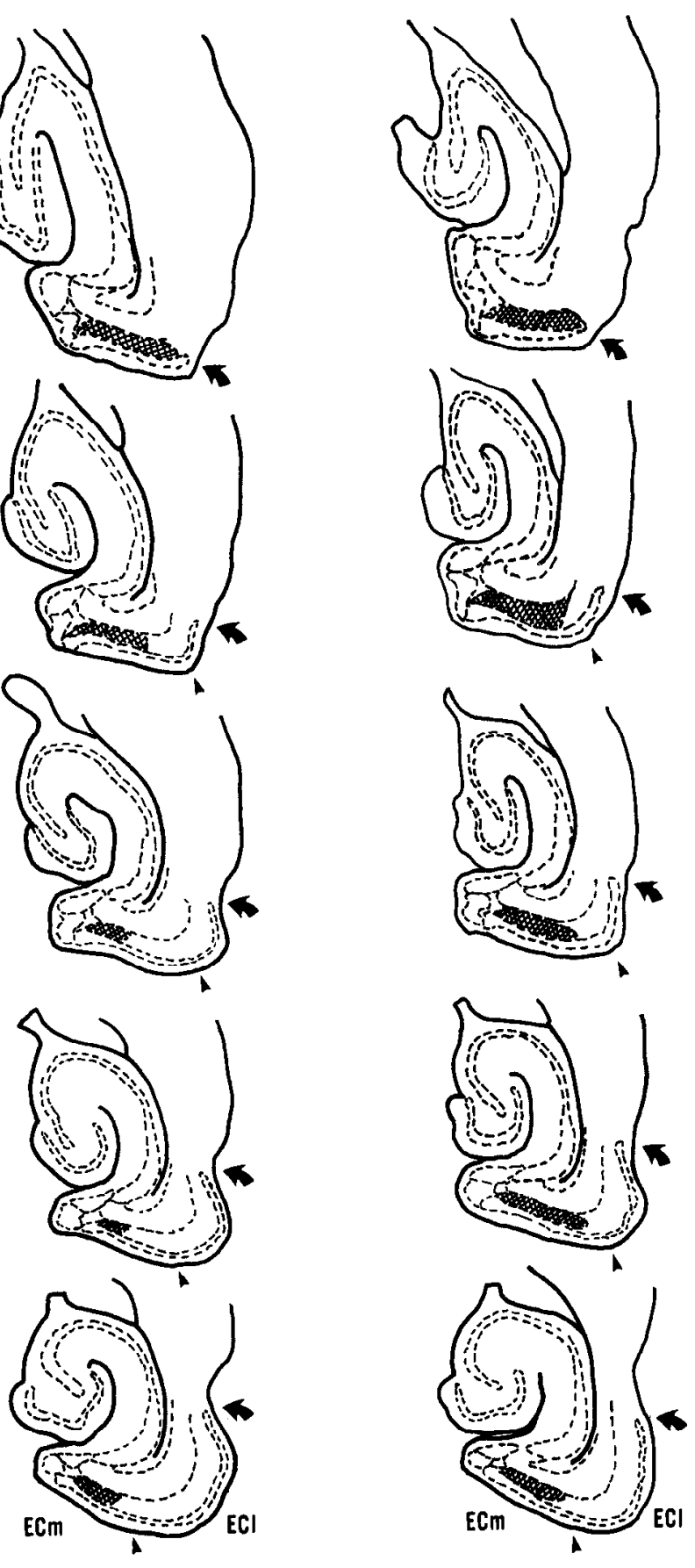

Lithium / Pilocarpine
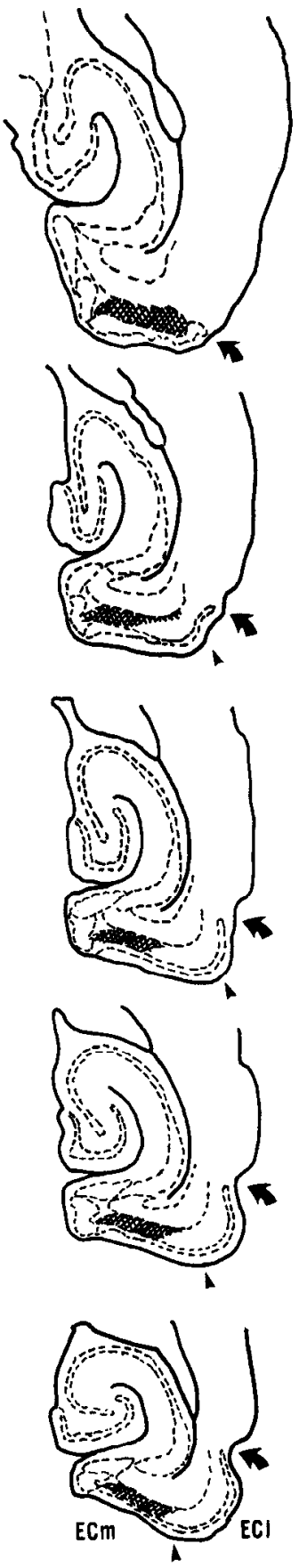

Neuronal loss in the EC of SSLSE, KA-, and lithium/ pilocarpine-injected rats

In Nissl-stained horizontal sections, loss of neurons was readily recognized in the EC of SSLSE, KA-, or lithium/pilocarpineinjected rats at $24 \mathrm{hr}$ after the treatments. The pattern of neurodegeneration in the EC was similar in all three models (Figs. $1,2)$. Therefore, the following description applies to all three experimental paradigms.

As illustrated in Figures 1 and 2, neurodegeneration was most

evident in layer III of the EC. In some cases, loss of neurons was also noticed in the deep layers (IV-VI), but neuronal damage was always more severe in layer III than in the deep layers. Ccll counting in KA-trcated rats revealed a significant decrease $(51-68 \%)$ in the total neuronal population in layer III as compared to normal rats at all three levels examined (Table 1). However, a few surviving neurons were frequently observed in the degenerated sector of layer III, even in the cases with the most severe neurodegeneration (cf. Figs. 1, 2, and 6). 
The preferential neuronal loss in layer III was found to occur in the medial EC, though the extent of neuronal damage in layer III along the mediolateral axis varied between cases (Figs. 1 and 2 ). Thus, in the majority of animals, loss of neurons was observed in the entire medial EC, with the most severe neurodegeneration in the most medial part of the region. In a few cases, neuronal loss was detected only in the most medial region of the EC.

Neuronal loss in the EC of SSLSE, KA-, or lithium/pilocarpine-injected rats was also assessed at different levels along the dorsoventral axis. Preferential loss of neurons in layer III was seen throughout the EC including both the dorsal and ventral portions (Figs. 1-3). The extent of the affected area within layer III tended to be greater towards the dorsal direction in most cases (cf. Fig. 3), but neurodegeneration appeared to be more severe in the ventral portion (cf. also Table 1).

The EC of SSLSE, KA-, and lithium/pilocarpine-injected rats killed 4 weeks after the induction of acute seizures showed a virtually identical pattern of neurodegeneration as that seen in rats perfused $24 \mathrm{hr}$ after the experimental treatments (Fig. 4). Thus, both the preferential neuronal loss and the typical survival of a few neurons in layer III of the medial FC was evident in all rats that were sacrificed at 4 weeks. In addition to neuronal loss, gliosis, as indicated by the apparent increase in the number of Nissl-stained glial nuclei, was present in the degenerated layer III in most cases (see, for example, Fig. $4 F, H$ ). Moreover, the $\mathrm{EC}$ of most experimental rats was apparently shrunken, as noted in the horizontal plane.

\section{Effects of diazepam/pentobarbital treatment on neuronal loss in the EC}

Diazepam and pentobarbital, administered $1 \mathrm{hr}$ after the injection of KA, abolished neurodegeneration in the EC in all rats studied. Thus, the density and morphology of neurons in the EC of these rats appeared identical to those observed in saline-injected controls (Fig. 5). Anticonvulsive treatment, when given $1 \mathrm{hr}$ after the onset of KA-induced forelimb convulsions (i.e., approximately $2.5 \mathrm{hr}$ after KA administration) prevented neuronal loss in the EC in seven of nine rats studied. Two rats in this group showed neurodegeneration in the $\mathrm{EC}$, but neuronal loss was only noticed in the most medial region of layer III and was limited to the ventral portion of the medial EC (micrograph not shown).

\section{Parvalbumin-immunoreactivity in the EC of normal, and $K A$ -} and lithium/pilocarpine-injected rats

In the EC of normal rats, parvalbumin-i was localized to a subpopulation of neurons, which were distributed throughout the region. The highest density of immunostained neurons was observed in layers II and III (Fig. 6A). In layer III, immmunoreactive neurons accounted for $8-12 \%$ of the total neuronal population (cf. Table 1). Notably, the proportion of immunoreactive neurons in the total neuronal population in layer III was higher in the dorsal and middle than in the ventral level of the EC (cf. Table 1). The morphology of most immunoreactive neurons did not resemble that of pyramidal cells seen in Golgi preparations (Lorente de Nó, 1933). In layers II and III, many parvalbumin-i neurons had an oval perikaryon, with processes often arising from two poles of the cell body and coursing perpendicular to the long axis of the lamina. Immunoreactive ncurons of this type were also observed in layer IV, but their cell bodies and processes were generally aligned parallel to the layer in the horizontal plane. Other parvalbumin-i neurons, including those in layers V and VI, were frequently multipolar or round in shape, and their processes extended into different directions. In addition, a plexus of processes containing parvalbumin-i was noticed in layer III and particularly in layer II.

Examination of immunostained sections from SSLSE, KA-, or lithium/pilocarpine-injected rats ( $24 \mathrm{hr}$ survival) revealed that the distribution pattern of parvalbumin-i neurons in the EC was similar to that seen in normal animals. In Nissl-counterstained sections, it was evident that many surviving neurons in the degenerated layer III were parvalbumin positive (Fig. $6 B-D$ ). Cell counting in KA-treated rats showed that the population of parvalbumin-i neurons was decreased, but the loss was relatively moderate (between $20 \%$ and $24 \%$ ) and quantitatively similar at the three levels analyzed. Thus, the number of parvalbumin-i neurons relative to the total neuronal population in KA-treated rats increased by approximately threefold as compared to normal rats (Table 1). This indicated a relative resistance of parvalbumin-containing neurons to seizure-related damage.

\section{Discussion}

The principal findings of the present study are: (1) a preferential loss of neurons in layer III in the medial FC exists in three established rat models of chronic epilepsy, (2) prolonged seizures are likely to be responsible for neurodegeneration in the $\mathrm{EC}$, and (3) neurons containing parvalbumin-i are relatively resistant to the pathophysiological processes that destroy the majority of neurons in layer III of the EC.

\section{Prolonged seizures and preferential destruction of layer III neurons in the medial EC}

The present study revealed in three rat models of chronic epilepsy a consistent and pronounced loss of neurons in layer III of the EC. The degeneration of layer III neurons, which was also briefly noted in earlier studies using KA (Nadler et al., 1978; Schwob et al., 1980), was permanent, since it was clearly demonstrable at 4 weeks after each of the experimental treatments.

Previous studies by several groups of investigators have shown that the brain damage following persistent electrical stimulation of the perforant path (Sloviter, 1983) or after the administration of KA or lithium/pilocarpine (Ben Ari et al., 1980; Olney et al., 1986; Sutula et al., 1992; Kelly and McIntyre, 1994) is seizure related. Thus, both KA- and lithium/pilocarpine-induced neuronal degeneration in several brain regions can be either prevented or reduced by treatment with anticonvulsants, including diazepam and pentobarbital. It has also been noted that sustained seizures, regardless of the method of seizure generation, consistently cause neuronal damage when they last more than $1 \mathrm{hr}$ (Olney et al., 1986). In agreement with these studies, our experiments, using pharmacological intervention at two different time points following the administration of KA, indicate that neurodegeneration in layer III of the EC likely also resulted from prolonged seizures, which had persisted for more than 1 hr. Moreover, it appears that the duration of convulsive seizures necessary for producing neuronal damage in the EC is less than $4 \mathrm{hr}$, since anticonvulsive treatment at this timepoint did not prevent $\mathrm{EC}$ lesions in lithium/pilocarpine-treated rats. The idea that neurodegeneration in the EC is associated with seizures is further supported by the fact that a subconvulsive dose of KA $(6 \mathrm{mg} / \mathrm{kg}$, s.c.) or a combination of lithium and scopolamine caused neither behavioral seizures nor neuronal loss in the EC.

There are other reasons to believe that a common feature of 

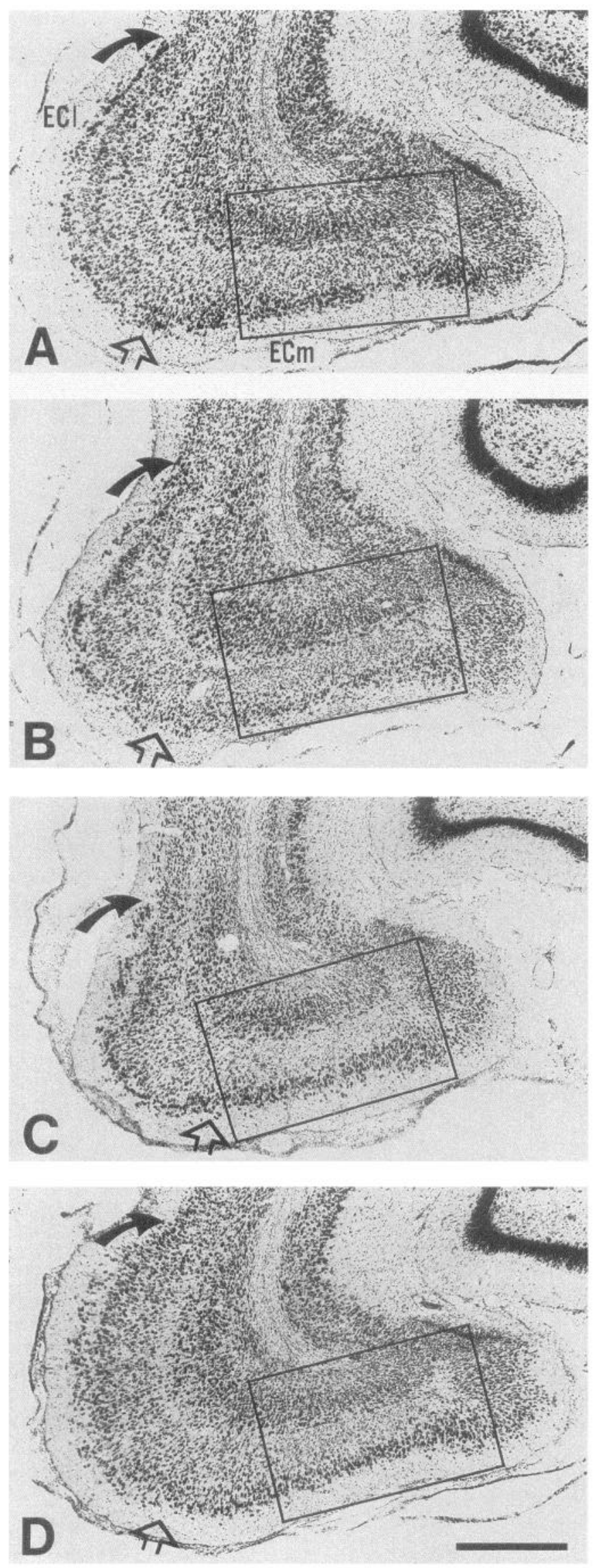

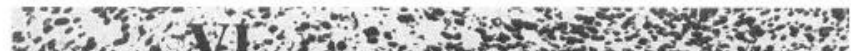
3.

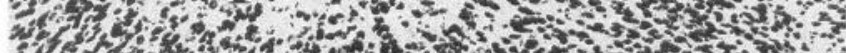

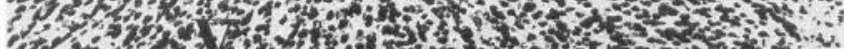

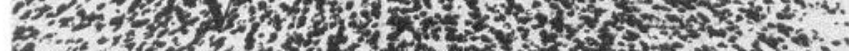

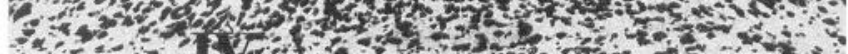

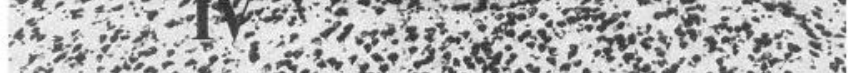

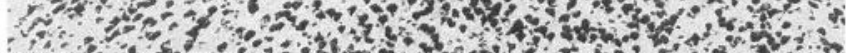

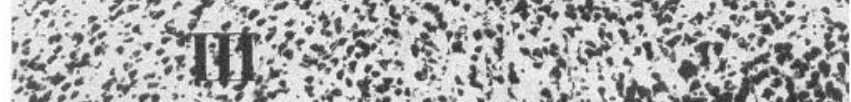

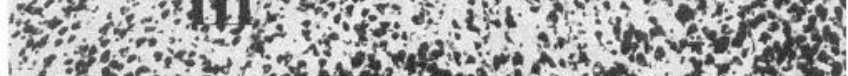

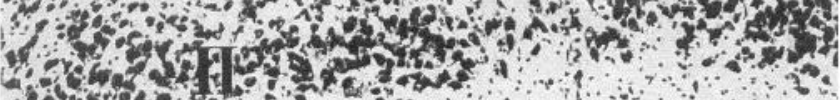
Fon

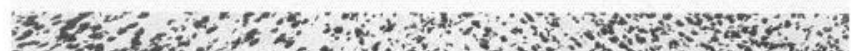

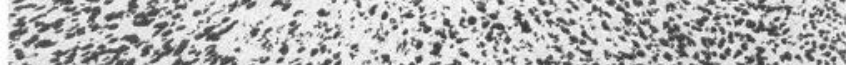

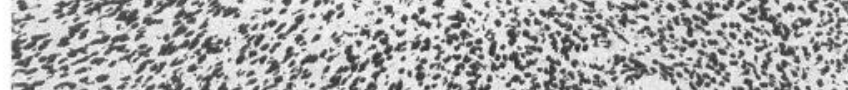

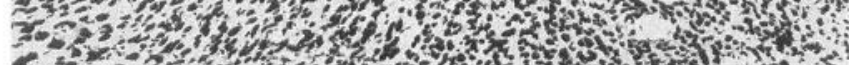

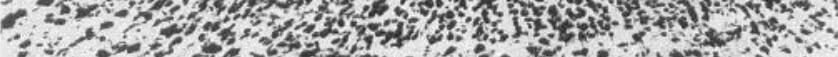

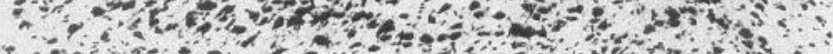

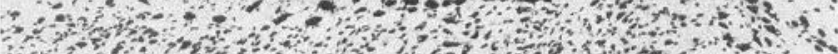

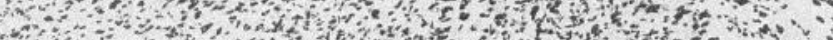

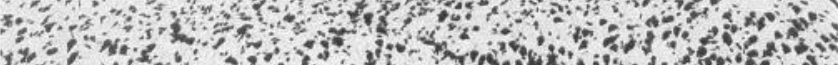

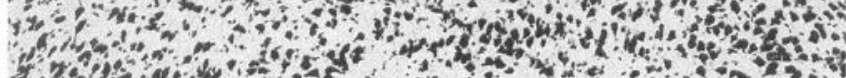

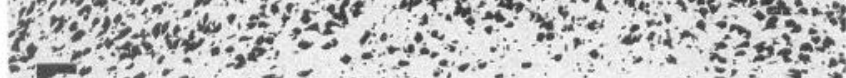
7 - -4

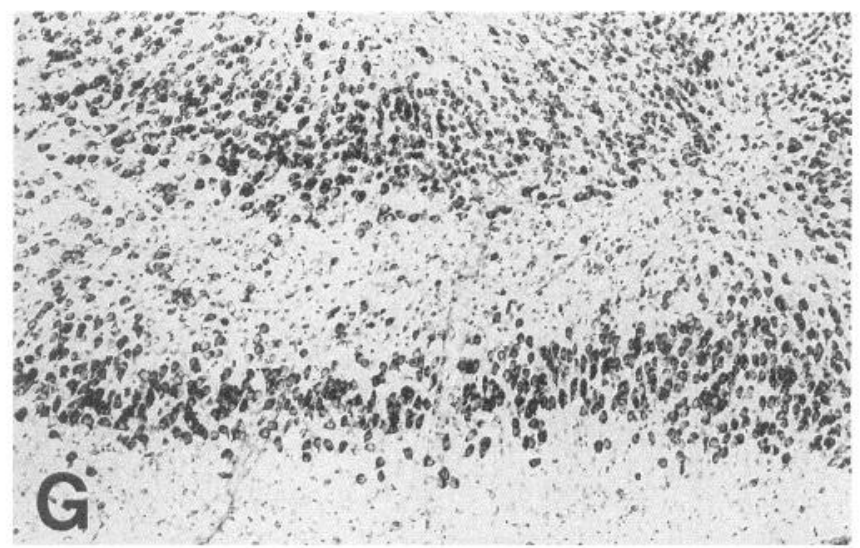

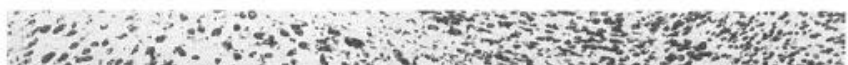

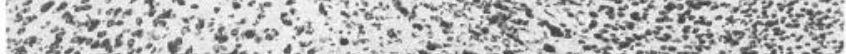

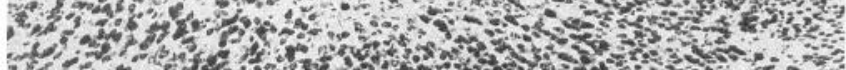

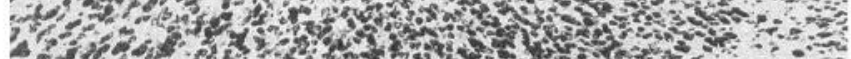

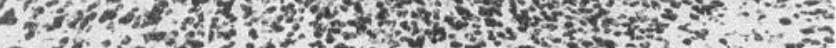

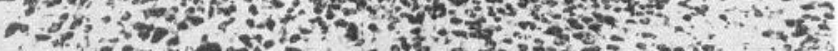

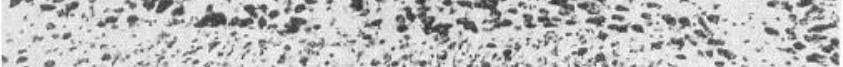

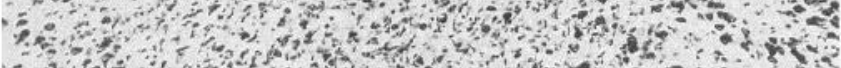

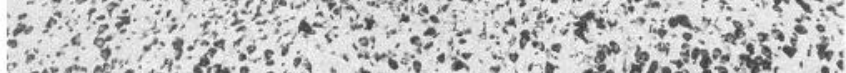

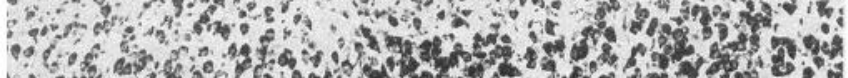

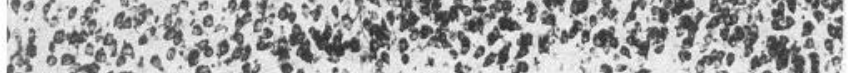

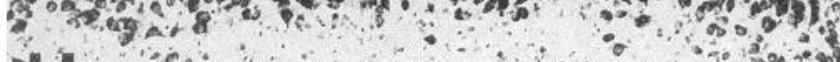
i1 

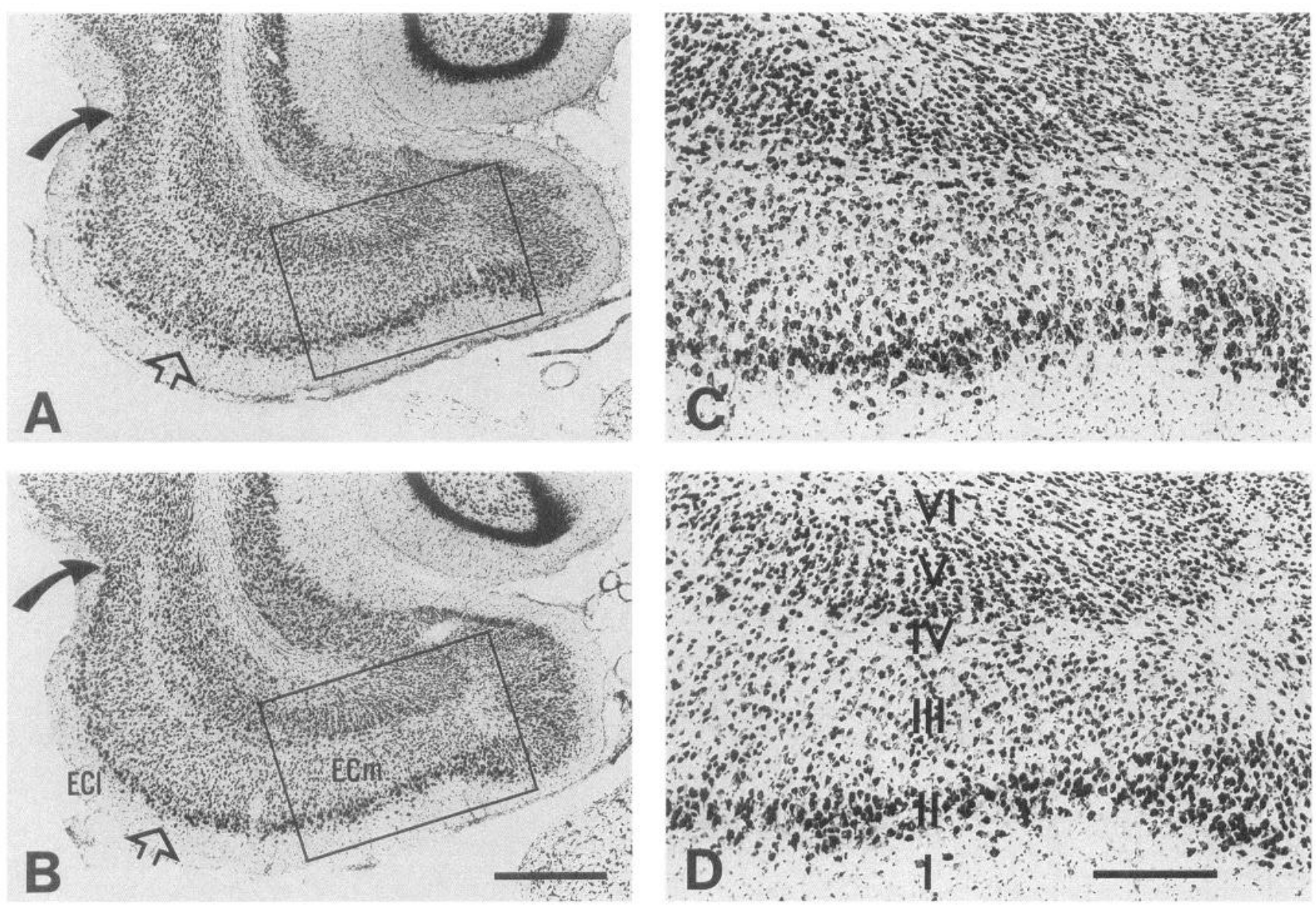

Figure 5. Nissl-stained horizontal sections $(30 \mu \mathrm{m})$ through the ventral level of the entorhinal cortex (EC) from a rat injected with KA followed by treatment with diazepam/pentobarbital $1 \mathrm{hr}$ later $(A$ and $C$ ) and a saline-treated control rat $(B$ and $D)$. $C$ and $D$ are high magnifications of the areas outlined by the boxes in $A$ and $B$, respectively. Note the absence of neuronal loss in layer III of the medial EC in $A$ and $C$ (cf. also Fig. $2 C, G)$. The solid arrows in $A$ and $B$ point to the lateral limit of the EC, and the open arrows indicate the approximate border between the medial $(E C m)$ and lateral $(E C l)$ EC. $I-V I$ : layers of the EC. Scale bars: $500 \mu \mathrm{m}$ in $A$ and $B ; 200 \mu \mathrm{m}$ in $C$ and $D$.

the three models underlies the neuronal death in the EC. First, in spite of distinct differences in the trigger mechanisms (electrical stimulation or activation of kainate or muscarinic cholinergic receptors), a virtually identical pattern of neuronal loss in the EC was present in all three models. Second, neurodegeneration was always preceeded by a bout of acute status epilepticus, which began approximately $1 \mathrm{hr}$ after the treatment and lasted for several hours. Third, neurodegeneration in the EC in all three models took place within $24 \mathrm{hr}$, in agreement with previous reports that irreversible damage to nerve cells occurs very rapidly after an episode of status epilepticus (Olney et al., 1986; Auer and Siesjö, 1988; Ingvar et al., 1988). Finally, functional mapping experiments using 2-deoxyglucose autoradiography have previously shown an involvement of the medial EC in the status epilepticus in the SSLSE and the KA models (Lothman and
Collins, 1981; VanLandingham and Lothman, 1991). Multiple lines of evidence therefore strongly suggest that the lesion in layer III of the EC described here is a direct consequence of prolonged seizure activity and is independent of the method of initial seizure generation.

\section{Mechanisms of seizure-related neurodegeneration in the EC}

It is not immediately apparent why neurons in layer III of the medial EC are preferentially susceptible to prolonged seizure activity. Evidence from various seizure models suggests that seizure-related brain damage is excitotoxic in nature, i.e., that neuronal death is caused by an overactivation of membrane receptors for excitatory amino acids (Olney et al., 1986). In particular, the neuronal loss in the olfactory cortex, which occurs in several models of limbic seizures, has been linked to $N$-methyl-D-as-

$\leftarrow$

Figure 4. Photomicrographs of Nissl-stained horizontal sections $(30 \mu \mathrm{m})$ cut through the ventral portion of the entorhinal cortex (EC) from a saline-treated $(A)$, a SSLSE $(B)$, a KA $(C)$ - and a lithium/pilocarpine $(D)$-injected rat that survived for 4 weeks after the treatment. $E$ - $H$ are higher magnifications of the areas outlined by the boxes in $A-D$, respectively. The pattern of neurodegeneration in the EC is virtually identical to that observed in rats killed $24 \mathrm{hr}$ after the treatment (cf. Figs. 1 and 2). Note the large numbers of Nissl-stained glial nuclei, indicating gliosis in the degenerated layer III $(F$ and $H$ ). The solid arrows in $A-D$ point to the lateral limit of the EC, and the open arrows indicate the approximate border between the medial $(E C m)$ and lateral $(E C l)$ EC. $I-V I$ : layers of the EC. Scale bars: $500 \mu \mathrm{m}$ in $D$ and also for $A-C ; 200 \mu \mathrm{m}$ in $H$ and also for $E-G$. 

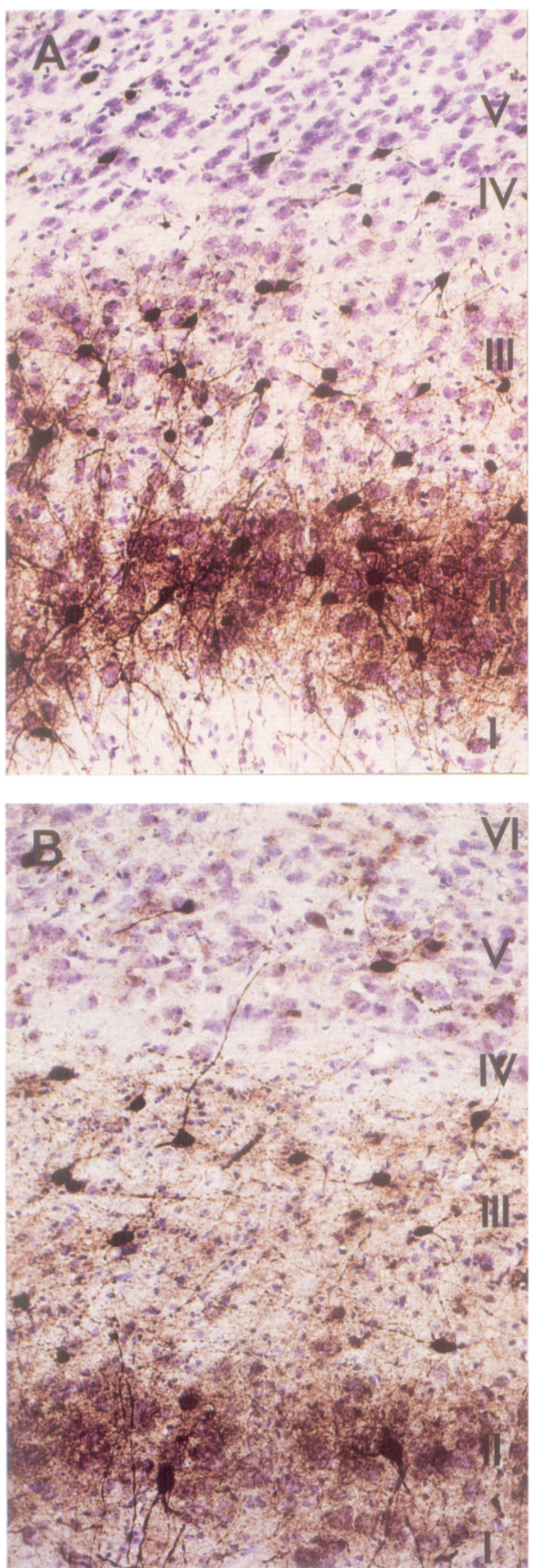
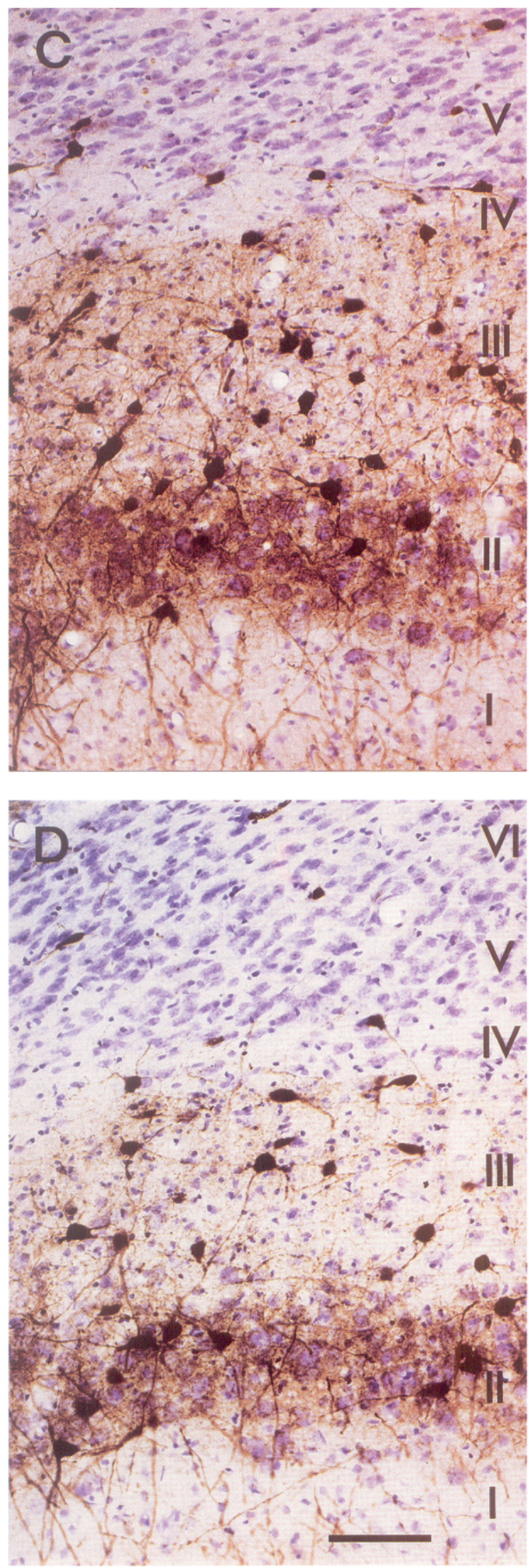
partate (NMDA) receptors based on the use of NMDA receptor antagonists as neuroprotective agents (Clifford et al., 1990). The notion of a critical involvent of NMDA receptors in the death of EC layer III neurons is also strongly supported by studies with the indirect excitotoxin aminooxyacetic acid (AOAA). When injected directly into the rat EC, this compound causes an episode of status epilepticus followed by a preferential neurodegeneration in layer III of the medial EC (Du and Schwarcz, 1992). This lesion is virtually identical to the EC neuropathology described in the present study and can be completely prevented by cotreatment with the NMDA receptor antagonist MK- 801 (Eid et al., 1995).

The relative resistance of parvalbumin-containing neurons in layer III described here also suggests that excitotoxic mechanisms are responsible for seizure-related neurodegeneration in the EC. A rise in intracellular free $\mathrm{Ca}^{2+}$ concentrations is commonly believed to constitute an essential and critical component in the neurodestructive cascade initiated by excitatory amino acid receptor overactivation (Choi, 1988). This pathological $\mathrm{Ca}^{2+}$ accumulation is likely to be less pronounced in the presence of parvalbumin, which is capable of binding $\mathrm{Ca}^{2+}$ effectively (Blaustein, 1988). Similar arguments regarding endogenous neuroprotection have been made in another instance of seizure-related neurodegeneration, i.e., in the hippocampal CA1 region, where parvalbumin-positive neurons survive preferentially amidst highly vulnerable pyramidal neurons (Sloviter, 1989).

No detailed study of the distribution of NMDA receptors or the expression of NMDA receptors subunits has heen performed in the rat EC. Currently available information does not indicate a particularly dense population of functional NMDA receptor on layer III neurons, but future studies with high cellular resolution and novel molecular probes for NMDA receptor subunits may yet help explain the preferential vulnerability of these cells to prolonged limbic seizures. An alternative possibility is that layer III neurons receive a disproportionally dense excitatory input in the limbic seizure circuit, and that excessive glutamate, released during status epilepticus, may preferentially bombard layer III neurons. Indeed, a putatively glutamatergic monosynaptic input from the presubiculum to the medial portion of layer III has been described (Köhler, 1985; van Groen and Wyss, 1990; CaballeroBleda and Witter, 1993).

\section{Functional implications of neuronal damage in EC layer III}

Several lines of evidence indicate that the EC is involved in epileptogenesis. In animal experiments, electrolytic lesions, local administration of chemoconvulsants, or electrical stimulation of the EC can induce acute seizures in the hippocampus (Dasheiff and McNamara, 1982; Collins et al., 1983). Repeated electrical stimulation of the perforant path, the most prominent excitatory pathway from the EC to the hippocampus, not only elicits acute hippocampal seizures but also causes selective neuronal damage in the hippocampus (Sloviter, 1983). Moreover, a slowly developing loss of paired pulse inhibition, indicating disturbed GA-
BAergic neurotransmission and subsequent hyperexcitability, is detected in the hippocampus following $\mathrm{EC}$ lesions (Bekenstein and Lothman, 1991).

Clinical observations have also provided evidence that a dysfunction of the EC may be associated with intractable temporal lobe epilepsy (Deutch et al., 1991; Spencer and Spencer, 1994). For example, space-occupying lesions in parahippocampal regions including the EC can slowly give rise to temporal lobe seizures even when the hippocampus displays little or no Ammon's horn sclerosis (Kim et al., 1990; Lévesque et al., 1991; Spencer, 1994). Rutecki and colleagues (1989) have documented that stimulation of the EC in patients undergoing temporal lobectomy evokes a hippocampal response that is virtually identical to spontaneously occurring interictal spikes. Moreover, a relatively high susceptibility to electrical stimulation has been noticed in the EC of patients with temporal lobe epilepsy (Wilson et al., 1990). In patients with intractable temporal lobe epilepsy, removal of the EC during anterior temporal lobectomy appears to be essential for controlling complex partial seizures (Goldring et al., 1992), again suggesting that the EC may contain epileptic foci or the neuronal circuitry necessary for seizure activity. In this context, it is particularly noteworthy that prominent, preferential loss of neurons is found in layer III of the medial EC in some patients suffering from intractable temporal lobe epilepsy (Du et al., 1993a).

Anatomical studies support a role of the $\mathrm{EC}$ in the origination and progagation of limbic seizures. In rats (Steward and Scoville, 1976), cats (Witter et al., 1989), and monkeys (Witter and Amaral, 1991), two fiber systems project from the EC to the hippocampus. One projection, the perforant path, which constitutes the first portion of the classic trisynaptic circuit, originates from neurons in EC layer II and terminates on dentate granule cells, and has been central to many considerations regarding normal and abnormal hippocampal function (Andersen, 1975). A second, monosynaptic pathway arises from neurons in layer III of the EC and projects directly to the hippocampal CA1 and the subiculum. This pathway may correspond to that shown to have a lower threshold for excitation than the trisynaptic pathway (Yeckel and Berger, 1990) and may thus be involved in the pathophysiology of hippocampal seizures.

The neuronal loss in layer III of the EC described here will not only affect direct postsynaptic hippocampal targets, since the $\mathrm{EC}$ and the hippocampal formation have reciprocal connections (Köhler, 1986, 1988; Witter et al., 1989), which may form a loop with the potential for reverberatory activity (Lopes da Silva et al., 1990; Lothman et al., 1991; Paré et al., 1992; Jones, 1993; Spencer and Spencer, 1994). Thus, destruction of neurons in layer III is likely to affect neural communication between layers in the EC and to influence the hypothetical EC-hippocampal loop. In principle, an EC layer III lesion may have antiepileptogenic consequences similar to those elicited acutely by the "pharmacological lesion," which is caused by an injection of tetrodotoxin into the EC (Stringer and Lothman, 1992). Recent studies in our laboratories have shown, however, that the neu-

Figure 6. Photomicrographs of the medial entorhinal cortex (EC) at the middle level along the dorsoventral axis. Horizontal sections (30 $\mu \mathrm{m})$ were taken from a normal $(A)$, a SSLSE $(B)$, a KA $(C)$-, and a lithium/pilocarpine $(D)$-injected rat that survived for $24 \mathrm{hr}$ after the treatment. The sections were processed for parvalbumin immunohistochemistry, and were subsequently counterstained with thionin (see text for methodological details). In the normal rat EC $(A)$, neurons containing parvalbumin-immunoreactivity $(-i)$ are mainly present in layers II and III. Note that the majority of neurons in layer III disappeared after experimental treatments $(R-D)$. In contrast, the distribution pattern and numbers of parvalbumin-i neurons in the degenerated area appear similar to those seen in $A$. I-VI: layers of the EC. Scale bars: $70 \mu \mathrm{m}$ in $D$ and also for $A-C$. 
ronal loss described here is more likely to promote epileptogenesis. Thus, AOAA-induced lesions in layer III of the EC result in an upregulation of hippocampal excitatory amino acid receptors (Tamminga et al., 1994), and cause distinct hippocampal neuropathology (Du et al., 1994) and an increased excitability of hippocampal neurons (unpublished observation). It is therefore conceivable that overexcitation of and/or damage to EC layer III neurons, perhaps in concert with hippocampal dysfunction, may play a significant role in epileptogenesis.

\section{References}

Andersen $P$ (1975) Organization of hippocampal neurons and their interconnections. In: The hippocampus (Isaacson RL, Pribram KH, eds), pp 155-175. New York: Plenum.

Auer RN, Siesjö BK (1988) Biological differences between ischemia hypoglycemia, and epilepsy. Ann Neurol 24:699-707.

Babb TL, Brown WJ (1987) Pathological findings in epilepsy. In: Surgical treatment of the epilepsies (Engel J Jr, ed), pp 511-540. New York: Raven.

Bekenstein JW, Lothman EW (1991) The role of the perforant pathway as a trophic factor for neurotransmission in the rat dentate gyrus. Hippocampus 1:405-413.

Bekenstein JW, Lothman EW (1993) Dormancy of inhibitory interneurons in a model of temporal lobe epilepsy. Science 259:97-100.

Ben-Ari Y (1985) Limbic seizures and brain damage produced by kainic acid: mechanisms and relevance to human temporal lobe epilepsy. Neurnscience 14:375-403.

Ben-Ari Y, Tremblay E, Ottersen OP, Meldrum BS (1980) The role of epileptic activity in hippocampal and 'remote' cerebral lesions induced by kainic acid. Brain Res 191:79-97.

Bertram EH, Lothman EW, Lenn NJ (1990) The hippocampus in experimental chronic epilepsy: a morphometric analysis. Ann Neurol $27: 43-48$

Blaustein MP (1988) Calcium transport and buffering in neurons. Trends Neurosci 11:438-443.

Bruton CJ (1988) The neuropathology of temporal lobe epilepsy. New York: Oxford UP.

Caballero-Bleda M, Witter MP (1993) Regional and laminar organization of projections from the presubiculum and parasubiculum to the entorhinal cortex: an anterograde tracing study in the rat. J Comp Neurol 328:115-129.

Cavalheiro EA, Riche DA, Le Gal La Salle G (1982) Long-term effects of intrahippocampal kainic acid injection in rats: a method for inducing spontaneous recurrent seizures. EEG Clin Neurophysiol 53: 581-589.

Cavalheiro EA, Leite JP, Bortolotto ZA, Turski WA, Ikonomidou C, Turski L (1991) Long-term effects of pilocarpine in rats: structural damage of the brain triggers kindling and spontaneous recurrent seizures. Epilepsia 32:778-782.

Celio MR (1986) Parvalbumin in most $\gamma$-aminobutyric acid-containing neurons of the rat cerebral cortex. Science 231:995-997.

Choi DW (1988) Calcium-mediated neurotoxicity: relationship to specific channel types and role in ischemic damage. Trends Neurosci 11: $465-469$.

Clifford DB, Olney JW, Maniotis A, Collins RC, Zorumski CF (1987) The functional anatomy and pathology of lithium-pilocarpine and high-dose pilocarpine seizures. Neuroscience 23:953-968.

Clifford DB, Olney JW, Benz AM, Fuller TA, Zorumski CF (1990) Ketamine, phencyclidine, and MK-801 protect against kainic acidinduced seizure-related brain damage. Epilepsia 31:382-390.

Collins RC, Tearse RG, Lothman EW (1983) Functional anatomy of limbic seizures: focal discharges from medial entorhinal cortex in rat. Brain Res 280:25-40.

Dasheiff RM, McNamara JO (1982) Electrolytic entorhinal lesions cause seizures. Brain Res 231:444-450.

Deutch C, Spencer S, Robbins R, Cicchetti D, Spencer D (1991) Interictal spikes and hippocampal somatostatin levels in temporal lobe epilepsy. Epilepsia 32:174-178.

Du F. Schwarcz R (1992) Aminooxyacetic acid causes selective neuronal loss in layer III of the rat medial entorhinal cortex. Neurosci Lett 147:185-188.

Du F, Whetsell WO Jr, Abou-Khalil B, Blumenkopf B, I othman EW, Schwarcz R (1993a) Preferential neuronal loss in layer III of the entorhinal cortex in patients with temporal lobe epilepsy. Epilepsy Res 16:223-233.

Du F, Williamson J, Bertram E, Lothman E, Okuno E, Schwarcz R (1993b) Kynurenine pathway enzymes in a rat model of chronic epilepsy: immunohistochemical study of activated glial cells. Neuroscience 55:975-989.

Du F, Eid T, Schwarcz R (1994) Injection of aminooxyacetic acid into the rat entorhinal cortex causes postsynaptic neuronal damage in the hippocampus: a possible model of temporal lobe epilepsy. Soc Neurosci Abstr 20:595.6.

Eid T, Du F, Lothman EW, Köhler C, Schwarcz R (1993) Selective neuronal loss in layer III of the medial entorhinal cortex in three animal models of epilepsy. Soc Neurosci $\Lambda$ bstr 19:419.6.

Eid T, Du F, Schwarcz R (1995) Differential neuronal vulnerability to aminooxyacetic acid and quinolinic acid in the rat parahippocampal region. Neuroscience, in press.

Fuller TA, Olney JW (1981) Only certain anticonvulsants protect against kainate neurotoxicity. Neurobehav Toxicol Teratol 3:355-361.

Goldring S, Edwards I, Harding GW, Bernardo KL (1992) Results of anterior temporal lobectomy that spares the amygdala in patients with complex partial seizures. J Neurosurg 77:185-193.

Honchar MP, Olney JW, Sherman WR (1983) Systemic cholinergic agents induce seizures and brain damage in lithium-treated rats. Scicnce 220:323-325

Ingvar M, Morgan PF, Auer RN (1988) The nature and timing of excitotoxic neuronal necrosis in the cerebral cortex, hippocampus and thalamus due to flurothyl-induced status epilepticus. Acta Neuropathol (Berl) 75:362-369.

Jones RSG (1993) Entorhinal-hippocampal connections: a speculative view of their function. Trends Neurosci 16:58-64.

Kelly ME, McIntyre, DC (1994) Hippocampal kindling protects several structures from the neuronal damage resulting from kainic acid-induced status epilepticus. Brain Res 634: 245-256.

Kim JH, Guimaraes PO, Shen MY, Masukawa LM, Spencer DD (1990) Hippocampal ncuronal density in temporal lobe epilepsy with and without gliomas. Acta Neuropathol 80:41-45.

Köhler C (1985) Intrinsic projections of the retrohippocampal region in the rat brain. I. The subicular complex. J Comp Neurol 236: 504522.

Köhler C (1986) Intrinsic connections of the retrohippocampal region in the rat brain. II. The medial entorhinal area. J Comp Neurol 246: $149-169$.

Köhler C (1988) Intrinsic connections of the retrohippocampal region in the rat brain: III. The lateral entorhinal area. J Comp Neurol 271: 208-228.

Lévesque MF, Nakasato N, Vinters HV, Babb TL (1991) Surgical treatment of limbic epilepsy associated with extrahippocampal lesions: the problem of dual pathology. J Neurosurg 75:364-370.

Lopes da Silva FH, Witter MP, Boeijinga PH, Lohman AHM (1990) Anatomic organization and physiology of the limbic cortex. Physiol Rev 70:453-511.

Lorente de Nó R (1933) Studies on the structure of the cerebral cortex. J Psychol Neurol 45:381- 438.

Lothman EW, Collins RC (1981) Kainic acid induced limbic seizures: metabolic, behavioral, electroencephalographic and neuropathological correlates. Brain Res 218:299-318.

Lothman EW, Bertram EH III (1993) Epilcptogenic effects of status epilepticus. Epilepsia 34(Suppl 1):S59-S70.

Lothman EW, Bertram EH, Bekenstein JW, Perlin JB (1989) Self-sustaining limbic status epilepticus induced by 'continuous' hippocampal stimulation: electrographic and behavioral characteristics. Epilepsy Res 3:107-119.

Lothman EW, Bertram EH, Kapur J, Stringer JL (1990) Recurrent hippocampal seizures in the rat as a chronic sequela to limbic status epilepticus. Epilepsy Res 6:110-118.

Lothman EW, Bertram EH III, Stringer JL (1991) Functional anatomy of hippocampal seizures. Prog Neurobiol 37:1-82.

Margerison JH, Corsellis JAN (1966) Epilepsy and the temporal lobes: a clinical, electroencephalographic and neuropathological study of the brain in epilepsy, with particular reference to the temporal lobes. Brain 89:499-530.

Meldrum BS, Bruton CJ (1992) Epilepsy. In: Greenfield's neuropathology (Adams JH, Duchen LW, eds), pp 1246-1283. New York: Oxford UP. 
Nadler JV (1981) Kainic acid as a tool for the study of temporal lobe epilepsy. Life Sci 29:2031-2042.

Nadler JV, Perry BW, Cotman CW (1978) Intraventricular kainic acid preferentially destroys hippocampal pyramidal cells. Nature 271:676677.

Nitsch C, Scotti A, Sommacal A, Kalt G (1989) GABAergic hippocampal neurons resistant to ischemia-induced neuronal death contain the $\mathrm{Ca}^{2+}$-binding protein parvalbumin. Neurosci Lett 105:263-268.

Olney JW, Collins RC, Sloviter RS (1986) Excitotoxic mechanisms of epileptic brain damage. In: Advances in neurology, Vol 44 (DelgadoEscueta AV, Ward AA Jr, Woodbury DM, Porter RJ, eds), pp 857877. New York: Raven.

Paré $\mathrm{D}$, deCurtis $\mathrm{M}$, Llinás $\mathrm{R}$ (1992) Role of the hippocampal-entorhinal loop in temporal lobe epilepsy: extra- and intracellular study in the isolated guinea pig brain in vitro. J Neurosci 12:1867-1881.

Rutccki PA, Grossman RG, Armstrong D, Irish-Loewen S (1989) Electrophysiological connections between the hippocampus and entorhinal cortex in patients with complex partial seizures. J Neurosurg 70: $667-675$.

Scharfman HE, Schwartzkroin PA (1989) Protection of dentate hilar cells from prolonged stimulation by intracellular calcium chelation. Science 246:257-260.

Schwob JE, Fuller T, Price JL, Olney JW (1980) Widespread patterns of neuronal damage following systemic or intracerebral injections of kainic acid: a histological study. Neuroscience 5:991-1014.

Sloviter RS (1983) "Epileptic" brain damage in rats induced by sustained electrical stimulation of the perforant path. I. Acute electrophysiological and light microscopic studies. Brain Res Bull 10:675697.

Sloviter RS (1987) Decreased hippocampal inhibition and a selective loss of interneurons in experimental epilepsy. Science 235:73-76.

Sloviter RS (1989) Calcium-binding protein (calbindin-D28K) and parvalbumin immunocylochemistry: localization in the rat hippocampus with specific reference to the selective vulnerability of hippocampal neurons to seizure activity. J Comp Neurol 280:183-196.

Sloviter RS (1991) Permanently altered hippocampal structure, excitability, and inhibition after experimental status epilepticus in the rat: the "dormant basket cell" hypothesis and its possible relevance to temporal lobe epilepsy. Hippocampus 1:41-66.

Sloviter RS (1994) The functional organization of the hippocampal dentate gyrus and its relevance to the pathogenesis of temporal lobe epilepsy. Ann Neurol 35:640-654.

Sommer W (1880) Erkrankung des Ammonshorns als aetiologisches Moment der Epilepsie. Arch Psychiatr Nervenkr 10:631-675.

Spencer DD (1994) Classifying the epilepsies by substrate. Clin Neurosci 2:104-109.

Spencer SS, Spencer DD (1994) Entorhinal-hippocampal interactions in medial temporal lobe epilepsy. Epilepsia 35:721-727.
Steward O, Scoville SA (1976) Cells of origin of entorhinal cortical afferents to the hippocampus and fascia dentata of the rat. J Comp Neurol 169:347-370.

Stringer JL, Lothman EW (1992) Reverberatory seizure discharges in hippocarnpal-parahippocampal circuits. Exp Neurol 116:198-203.

Sutula T, Cavazos J, Golarai G (1992) Alteration of long-lasting structural and functional effects of kainic acid in the hippocampus by brief treatment with phenobarbital. J Neurosci 12:4173-4187.

Tamminga CA, Gao XM, Du F, Schwarcz R (1994) "Indirect excitotoxin" lesion of layer III in rat entorhinal cortex produces glutamate receptor changes in hippocampus. Soc Neurosci Abstr 20:213.20.

Turski L, Ikonomidou C, Turski WA, Bortolotto ZA, Cavalheiro EA (1989) Review: cholinergic mechanisms and epileptogenesis. The seizures induced by pilocarpine: a novel experimental model of intractable epilepsy. Synapse 3:154-171.

Turski WA, Cavalheiro EA, Schwarz M, Czuczwar SJ, Kleinrok Z, Turski L (1983a) Limbic seizures produced by pilocarpine in rats: behavioural, electroencephalographic and neuropathological study. Behav Brain Res 9:315-335.

Turski WA, Czuczwar SJ, Turski L (1983b) Cholinomimetics produce seizures and brain damage in rats. Experientia 39:1408-1411.

Turski WA, Cavalheiro EA, Coimbra C, da Penha Berzaghi M, Ikonomidou-Turski C, Turski L (1987) Only certain antiepileptic drugs prevent seizures induced by pilocarpine. Brain Res Rev 12:291-305.

Van Groen T, Wyss JM (1990) The connections of presubiculum and parasubiculum in the rat. Brain Res 518:227-243.

VanLandingham KE, Lothman EW (1991) Self-sustaining limbic status epilepticus. I. Acute and chronic cerebral metabolic studies: limbic hypermetabolism and neocortical hypometabolism. Neurology 41: $1942-1949$.

Wieser H-G, Engel J Jr, Williamson PD, Babb TL, Gloor P (1993) Surgically remediable temporal lobe epilepsy syndromes. In: Surgical treatment of the epilepsies (Engel J Jr, ed), pp 49-63. New York: Raven.

Wilson CL, Isokawa M, Babb TL, Crandall PH (1990) Functional connections in the human temporal lobe. I. Analysis of limbic system pathways using neuronal responses evoked by electric stimulation. Exp Brain Res 82:279-292.

Witter MP, Amaral DG (1991) Entorhinal cortex of the monkey: V. Projections to the dentate gyrus, hippocampus, and subicular complex. J Comp Neurol 307:437-459.

Witter MP, Groenewegen HJ, Lopes da Silva FH, Lohman AHM (1989) Functional organization of the extrinsic and intrinsic circuitry of the parahippocampal region. Prog Neurobiol 33:161-253.

Yeckel MF, Berger TW (1990) Feedforward excitation of the hippocampus by afferents from the entorhinal cortex: redefinition of the rolc of the trisynaptic pathway. Proc Natl Acad Sci USA 87:58325836. 